\title{
Building objectives and incorrect use of regulatory standards
}

\author{
Miroslav Sůra ${ }^{1, *}$ \\ ${ }^{1}$ CTU Prague, Faculty of Civil Engineering, Thakurova 7, 16629 Prague, Czech Republic
}

\begin{abstract}
European and other regulatory standards affect, besides everyday life, also planning, designing, and other building processes. Regulations alter, sometimes threaten, or even completely prevent, the achievement of the intended objectives of investors and other participants in building processes. Implementation of regulative standards may result in problems that cause various defects to planning-design-construction objectives. Such regulatory issues are known to have already caused ethical, social and financial burdens in other areas of human activity. In planning and construction processes, various participants may be the source of misuse problems - unintentionally or otherwise. A model of categories of problems is presented (and has been tested) - of misuse problems that result from potential conflicts between (EU) regulatory standards and objectives of participants in building processes. The categories have been compiled and compared also according to sources and actors of the problems. Protective strategies against incorrect application and/or misuse of regulations are in the process of formulation and verification, taking into account sources and actors in the problem categories. Finally, it helps and protects participants - especially as regards matters of technology, design phase, public attitudes, and money.
\end{abstract}

\section{Introduction}

We try to describe and categorize possible threats that may appear in association with application of regulations imposed on building processes. The concern was mainly focused on categorizing threats and problems related to regulations that are voluntarily adopted by (some of) the various building process participants. Compulsory regulations, however, are apt to raise threats that can be classified within the same categories, as stated below. We focus on external ("non-technological") threats and problems, originating in surroundings of the building processes - related to participants of any type: law makers, developers, investors, owners of products, adopters or applicators, etc.

To identify categories of the problems and threats, analogies found in various other areas were explored to this end, too. Finally, this builds the base for suggested ways how to avoid or resolve such problems and threats.

\footnotetext{
*Corresponding author: sura@fssv.cvut.cz
} 


\subsection{Questions, Quest \& Examples}

Building activities require a lot of intellectual work and other work (such as administrative or clerical work) in order to get the desired results. Further, such work is being performed within an environment of huge mass of juristic and other regulations. Can everyone understand and conduct the work adequately, with equal insight and comprehension of the objectives?

Where do the problems originate, what are the threats? Threat of unintentionally acting improperly, without full understanding of the objectives, using misleading interpretation, or in extreme cases acting with intention to misuse regulations and/or additional restrictions for side-effects - these are just some examples.

\section{Implementation phase threats}

Each party in a building process [1] may expect different effects. Participants [2] directly engaged in the project introduction obviously share mutually closer and more accurate views on (adopted) regulations than those joining the building process only in its later stages. Possible causes of this threat: insufficient experience, unrealistic expectations. If only partial information is available to some of the participants, they might disregard such information - this danger may lessen as more experience is acquired by the various parties.

Some of the adverse financial effects of regulations - whether mandatory or adopted regulations - may be detected in a relatively short period of time, and these may be subjected to continual correction by removing the cause: by modifying impacts, by readjusting expectations, by completing information (database) etc. And of course, the threat of adverse financial effects may be reduced by training participants, in-depth analysis, preparatory work, etc.

Long-lasting adverse (not only financial) effects may substantially influence participants' negative attitude towards future projects. This might be avoided by not allowing accumulation of adverse effects, but dealing with regulation drawbacks quickly and peremptorily.

\section{Intentions and actual constraints conflict}

The threats arise from the possibility that some of the participants exploit building activities or implement building industry processes without regard to the actual regulations. Although other participants do their best and follow actual constraints imposed by these regulations, a single participant can degrade the quality of final results. Typically such a participant's activities are not closely linked with other participants in a fairly short time period; as a consequence such inadequate irregularities may stay undetected for quite a long time and violate the due constraints.

The common case is that part of the project implementation differs from the original project, and these differences are not properly coordinated with other processes - only some of the processes are modified both with respect to appropriate regulations and project objectives.

\section{Threat of institutionalization}

It is human nature to act in such a way as to achieve - subjectively - the highest possible (not necessarily financial) benefits. No wonder that participants in building process will tend to apply regulations so as to maximize their individual subjective benefits. 
Any restrictions of state space available to a participant for his/her operations can only decrease his/her attainable benefits, never increase it. Such restrictions usually occur if some interest group has the ability to restrict the participant's set of available actions. One of or several cooperating participants may form such a group if he/she/it succeeds in taking over the control of the building process or of its part. Restrictions imposed on the weaker parties by such an interest group would not probably be very lasting if the weaker parties grow stronger as they gain more experience.

Long lasting effects of decreasing participants' benefits arise in case of interest groups that are usually external to building activities. Typical instance of such an external, institutional, interest group is legislation that can impose such regulations and constraints on building processes that reduce the manoeuvring space and disturb the balanced relations among participants. As a result, some participants are discriminated against others, which reduces their maximum achievable benefits. While the preferred participants collect their extra, unfair advantages.

\section{Statutory interventions}

This threat arises as one of the ramifications of 'good-doers' activities.

This threat is enabled by easiness of menial, unqualified, derogative and/or financially destabilizing interferences as practiced by authorities or subjects possessing delegated competences. These interferences may arise from actual or shamming statutory competences to impose regulations and constraints to building processes. Alternatively, the 'perpetrators of good' may push authorities to such interferences, and induce the above mentioned unfavourable ramifications in otherwise rewarding [3] building activities.

The goals of such interferences may be status build-up of the intervenor, pursuit for conveniences and benefits, or simply getting a backhander (racketeering). However, the most dangerous is probably one kind of good-doers-those ignorant enough to believe others to be incompetent and themselves to know better than most of the rest of humankind.

And again, building industry activities seem to be unprotected against this kind of threat. As a rule, to protect anything from 'perpetrators of good' is a rather difficult task.

\section{Inconsistent perception of meaning}

The terms (designations) and concepts in the context of unequal perception of meaning can be divided into two groups, with fuzzy dividing borders or with terms belonging to both groups. One of the groups contains terms used within building activities (professional terminology), the other group contains terms used in communication about building activities (including the lay public).

Inconsistent perception of meaning of building terminology should be rather fully eliminated in the long run-otherwise misunderstanding would be the source of various defects in the building process. The strict meaning of professional terms is consensually settled and the inexactness in communication disappears.

Inconsistent perception of meaning in communication about building activities is a different problem. This communication is performed mostly in natural language. Some inaccuracy in communication and unequal interpretation by various participants cannot be fully removed. This may easily cause unintended misunderstanding; such threat can be decreased by coordinated effort of participants, by reducing the inaccuracy in communication. Permanent threat lies in the fact that it enables intentional and managed misunderstanding - one or several participants, in their individual earnings efforts, deliberately seek for divergent interpretations and meanings of terms. Increased inexactness 
is used to induce unfavourable effects and defects, and this may end up in a court which is asked to explain the "proper" meaning.

\section{Threat of redefinitions}

This threat arises when regulations and constraints imposed on building project are interpreted by the participants having stronger positions so as to serve their own benefits $[4,5]$.

\subsection{Threat of reinterpretation}

One of participants, having a sufficiently strong position, may enforce changes in interpretation (meaning) of competences, goals, processes specifications, and so on, to depart it from customary standard interpretation of regulations and constraints. Such changes may adversely influence effectiveness of building processes as well as moral attitude of co-participants.

\subsection{Threat of reformulation}

One of participants, in a sufficiently strong position, may enforce changes in wording of competences, goals, processes specification, and so on, wording that is in contradiction to what has been previously agreed upon with respect to actual constraints and regulations. Likewise, this may also adversely influence effectiveness of building processes as well as moral attitude of co-participants.

\section{Customs and traditions threat}

Participants in building activities (planners, owners, investors, contractors, suppliers, facility management...) usually have gained experience and habits in their previous activities [6]. However, the environment, conditions and tenets of construction industry change rapidly, and to prevent participants from using insufficient and inadequate procedures, from using their old customs, beliefs or doctrines is ever more important. Neglecting this may degrade processes in the construction industry.

\section{Legal requirements misuse - rent-seeking threat}

This threat lies in setting up lobbies ('rent-seeking' groups) that push legal processes ending up in passing laws and regulations, constraints of which only the rent-seekers can comply with - thus creating effective monopolies or cartels. Or, these rent-seeking lobbies may transform existing legal requirements to suit their monopoly, enforce using their monopolistic claims, gadgets or tools, at the expense of others $[4,5]$. This limits (temporary only, in the better case) or destroys the building process objectives.

This type of threats is a well-known phenomenon and is 'exploited' in various areas, currently by needless fees, charges or just 'protection money' in such 'popular' domains as fighting against 'global warming', or 'climate change', unfounded and superfluous 'environmental protection', social and community projects (rather regularly failing to achieve the declared goals, like social housing construction), unavailing and wasted away support of various 'minority' and 'disadvantaged' groups, and many others. Currently, building industry activities seem to be unprotected from this kind of misuse, too.

And yes, rent-seeking threat is often bound closely to statutory interventions threat. 


\section{Encumbering participants}

This threat arises where authorized or accredited but corruptible body is in a position to (easily) generate superfluous requirements on participants. The goal of encumbering may be e.g. to prevent implementation of some objectives of a building project, in favour of the possibility to implement a competing project.

This threat seems to be similar to the one mentioned in 5 Statutory interventions, however it is not identical.

\section{Introducing conflicts externally}

One of the reasons why participants in a building industry project (sometimes) do not 'speak the same language' [7] is that they act at different areas or levels of detail.

The threat lies in the possibility that one of the participants is forced to acquire dominant position towards the others - forced by external factors or powers.

This threat also arises if the parties are forced, by external factors, to "battle for dollars' - to compete for a share of a limited resource pool.

\section{Case study}

Real names are omitted to avoid lawsuits for slander, libel or defamation. Therefore, the following should be considered a "possibility" even though it is listed as "facts".

It is a case of a settlement/town, with rural character and population slightly-or substantially-exceeding 5.000. Local authorities were assigned a task to build a wastewater treatment plant (WTP). With regard to relevant regulations, three locations were selected as rather equally suitable - an old unused local industrial facility, and two of undeveloped greenfield sites.

The winning WTP project was chosen to be placed on the old unused local industrial facility site. In addition to statutory regulations, the choice was based on subsidy (by EU funds) and other financial affordability. This imposed additional restrictions - a claim for a gift from public money (additional subsidy money) for revitalizing parts of the old industrial facility, while for greenfield sites no such subsidy was available.

A few years later, due to growing population both on working and non-working members, another task was set-to build health and care centre (HCC) and sports and recreational facilities (SRF). These had to be built on one of the greenfields although the old industrial facility would be much more suitable if still available and not already used for the WTP. It should be noted there were only highly unclear visions of HCC\&SRF at the time of WTP construction. But in retrospect, other uses for the old industrial facility could and should have been anticipated, and so it would have been better to swap the locations in case of WTP.

Some of the incorrect and disadvantageous use of regulations and constraints were identified as follows:

- Intentions and actual constraints conflict: although there are only unclear visions of HCC\&SRF at the time of WTP construction, a better use for the brownfield could and should be foreseen.

- Threat of institutionalization: subsidies (claims for other people's money) perceived and handled in a restrictive manner (old industrial facility preference) is an inappropriate approach from a long-term perspective. 
- Threat of reinterpretation: subsidies redefined to "recoverable advantage/money" discriminate the greenfield sites, adversely influence and cause defects of future projects, and effectivity and success thereof.

- Legal requirements misuse - rent-seeking threat: expanding WTP project to include and exploit subsidies highly discriminates the undeveloped greenfield sites as an option, but generates extra profit for the brownfield owners supporters (potential rent-seekers).

- Statutory interventions: working hand-in-hand with rent-seeking, this actually causes a synergistic effect eliminating undeveloped greenfield sites as options. But "gaining subsidies" is a tool for status build-up of bureaucracy and local politicians.

- Customs and traditions threat: The custom of yielding to restrictions/regulations without rational reconsidering, and the tradition of preferring brownfield to greenfield - both turn out to be counterproductive.

\section{Conclusions}

Incorrect use of regulations harms and causes defects in plans, building objectives and building process outcomes, and public attitude and view thereof. Being aware of these threats is the first step to avoiding them. Focusing attention of professionals and public on various sources of such threats has the potential to put (some of) these sources out of action. For this purpose, however, the threats need to be recognized in a real-world environment. We identify and define features of various threats and classify the threats according to such distinguishable features. Then the features and the corresponding threat can be discovered more easily in an actual case, and eventually the threat and its sources are successfully eliminated.

Support from various European projects and foundations is gratefully acknowledged.

\section{References}

1. B. Blackwell, Industrial strategy: government and industry in partnership. Available on https://www.gov.uk/government/uploads/system/uploads/attachment_data/file/34710/12 -1327-building-information-modelling.pdf

2. Team-of-authors, SMART (summer 2014). Available on http://www.sps.cz/RDS/_PDFDoc_2014/Smart-Leto\%20-2014.pdf

3. Legrand gr., Green building-Ecological construction. Available on http://www.legrand.com/EN/green-building-description_12850.html

4. Ch. W. Mills, White collar: the American middle classes (Oxford University Press, New York, 2002)

5. P. Hampl, White collar revisited, $\mathrm{PhD}$ thesis (Charles University, Prague, 2015)

6. S. Plous, The psychology of judgement and decision making (McGraw-Hill, Inc., New York, 1993)

7. T. Casey, Residential Energy Efficiency: Taking It To The Next Level. Available on https://greenbuildingelements.com/2017/05/31/residential-energy-efficiency-takingnext-level 